\title{
TASK Channels on Basal Forebrain Cholinergic Neurons Modulate Electrocortical Signatures of Arousal by Histamine
}

\author{
Michael T. Vu, ${ }^{1}$ Guizhi Du, ${ }^{3}$ Douglas A. Bayliss, ${ }^{4}$ and Richard L. Horner ${ }^{1,2}$ \\ Departments of ${ }^{1}$ Physiology and ${ }^{2}$ Medicine, University of Toronto, Toronto, Ontario M5S 1A8, Canada, ${ }^{3}$ Department of Anesthesiology, West China \\ Hospital of Sichuan University, Chengdu, Sichuan, China, and ${ }^{4}$ Department of Pharmacology, University of Virginia, Charlottesville, Virginia 22908
}

Basal forebrain cholinergic neurons are the main source of cortical acetylcholine, and their activation by histamine elicits cortical arousal. TWIK-like acid-sensitive $\mathrm{K}^{+}$(TASK) channels modulate neuronal excitability and are expressed on basal forebrain cholinergic neurons, but the role of TASK channels in the histamine-basal forebrain cholinergic arousal circuit is unknown. We first expressed TASK channel subunits and histamine Type 1 receptors in HEK cells. Application of histamine in vitro inhibited the acid-sensitive $\mathrm{K}^{+}$current, indicating a functionally coupled signaling mechanism. We then studied the role of TASK channels in modulating electrocortical activity in vivo using freely behaving wild-type $(n=12)$ and ChAT-Cre:TASK ${ }^{f f f}$ mice $(n=12)$, the latter lacking TASK-1/3 channels on cholinergic neurons. TASK channel deletion on cholinergic neurons significantly altered endogenous electroencephalogram oscillations in multiple frequency bands. We then identified the effect of TASK channel deletion during microperfusion of histamine into the basal forebrain. In non-rapid eye movement sleep, TASK channel deletion on cholinergic neurons significantly attenuated the histamine-induced increase in $30-50 \mathrm{~Hz}$ activity, consistent with TASK channels contributing to histamine action on basal forebrain cholinergic neurons. In contrast, during active wakefulness, histamine significantly increased $30-50 \mathrm{~Hz}$ activity in ChAT-Cre:TASK ${ }^{f f f}$ mice but not wild-type mice, showing that the histamine response depended upon the prevailing cortical arousal state. In summary, we identify TASK channel modulation in response to histamine receptor activation in vitro, as well as a role of TASK channels on cholinergic neurons in modulating endogenous oscillations in the electroencephalogram and the electrocortical response to histamine at the basal forebrain in vivo.

Key words: basal forebrain; histamine; sleep; TASK channels; wakefulness

Significance Statement

Attentive states and cognitive function are associated with the generation of $\gamma \mathrm{EEG}$ activity. Basal forebrain cholinergic neurons are important modulators of cortical arousal and $\gamma$ activity, and in this study we investigated the mechanism by which these neurons are activated by the wake-active neurotransmitter histamine. We found that histamine inhibited a class of $\mathrm{K}^{+}$leak channels called TASK channels and that deletion of TASK channels selectively on cholinergic neurons modulated baseline EEG activity as well as histamine-induced changes in $\gamma$ activity. By identifying a discrete brain circuit where TASK channels can influence $\gamma$ activity, these results represent new knowledge that enhances our understanding of how subcortical arousal systems may contribute to the generation of attentive states.

\section{Introduction}

TWIK-like acid-sensitive $\mathrm{K}^{+}$(TASK) channels mediate a leak conductance that controls cellular excitability (Enyedi and Czir-

Received April 13, 2015; revised Aug. 11, 2015; accepted Aug. 16, 2015.

Author contributions: M.T.V., G.D., D.A.B., and R.L.H. designed research; M.T.V. and G.D. performed research; M.T.V., G.D., D.A.B., and R.L.H. analyzed data; M.T.V., D.A.B., and R.L.H. wrote the paper.

This work was supported by the Canadian Institutes of Health Research Grant MT-15563 to R.L.H. and the National Institutes of Health Grants NS33583 and HL108609 to D.A.B., R.L.H. was supported by a Tier I Canada Research Chair in Sleep and Respiratory Neurobiology. M.T.V. was supported by Sleep and Biological Rhythms Toronto, a Canadian Institutes of Health Research-funded research and training program at the University of Toronto to R.L.H., as well as a Queen Elizabeth II Graduate Scholarship in Science and Technology.

The authors declare no competing financial interests.

Correspondence should be addressed to Dr. Richard L. Horner, 1 King's College Circle, Medical Sciences Building, Room 3206, Toronto, Ontario M5S 1A8, Canada. E-mail: richard.horner@utoronto.ca. ják, 2010). Dynamic modulation of TASK channels is thought to underlie changes in brain arousal state in wakefulness, sleep, and general anesthesia (Bayliss and Barrett, 2008; Franks, 2008; Steinberg et al., 2015).

TASK channel conductance is modulated by a variety of chemical signals and neurotransmitters, as well as clinically useful drugs (Talley and Bayliss, 2002; Lesage and Barhanin, 2011). For example, acidification inhibits TASK channels causing neuronal depolarization, whereas nitric oxide or volatile anesthetics (such as halothane) can activate TASK channels causing neuronal hy- 
perpolarization (Franks and Lieb, 1988; Patel et al., 1999; Sirois et al., 2000; Kang et al., 2007; Toyoda et al., 2008; Toyoda et al., 2010). At various levels of the neuraxis, neurotransmitters of the wake-active ascending arousal system, such as noradrenaline (Larkman and Perkins, 2005), serotonin (Weber et al., 2008), and orexin (Doroshenko and Renaud, 2009), also inhibit TASK channel conductance. Given that this ascending arousal system mediates forebrain activation and increased responsiveness to sensory stimuli (Lee and Dan, 2012), TASK channels may constitute a component of the system that modulates electrocortical activity in vivo.

A key change in electrocortical activity during arousal is a shift to higher frequencies (Moruzzi and Magoun, 1949), including the $\gamma(30-50 \mathrm{~Hz})$ frequency band that is associated with attentional states (Gross and Gotman, 1999; Fries et al., 2001). Basal forebrain cholinergic inputs onto cortical neurons can drive a shift toward $\gamma$ activity (Buzsaki et al., 1988; Goard and Dan, 2009) and promote an awake attentional state (Pinto et al., 2013). Importantly, basal forebrain cholinergic neurons are themselves driven by depolarizing inputs from the ascending arousal system (Semba et al., 1988). This includes histaminergic inputs from the tuberomamillary nucleus (Inagaki et al., 1988) that promote cortical arousal (Zant et al., 2012) as well as the maintenance of wakefulness, arousal, and conscious awareness (Nelson et al., 2002; John et al., 2004; Zecharia et al., 2012). Identifying whether histamine at the basal forebrain modulates electrocortical activity via TASK channels would be new knowledge regarding the modulation of the ascending arousal circuitry.

Here we test two hypotheses: (1) histamine inhibits a $\mathrm{K}^{+}$conductance characteristic of TASK channels; and (2) histamine acting upon basal forebrain cholinergic neurons promotes electrocortical signatures of arousal that depend on TASK channels. To address the first hypothesis, human embryonic kidney (HEK) 293 cells were transfected with histamine Type 1 receptors plus TASK-1 (KCNK3), TASK-3 (KCNK9), or heterodimeric TASK$1 / 3$ channels to identify whether histamine Type $1\left(\mathrm{H}_{1}\right)$ receptors can inhibit TASK channels. Although histamine-induced neuronal depolarization can involve suppressed $\mathrm{K}^{+}$leak conductance (McCormick and Williamson, 1991; Reiner and Kamondi, 1994; Li and Hatton, 1996), to our knowledge, a TASK-mediated mechanism has not previously been identified. To address the second hypothesis, we used mice in which TASK channel subunits were deleted from cholinergic neurons, henceforth referred to as ChAT-Cre:TASK ${ }^{f / f}$ mice (Lazarenko et al., 2010). In freely behaving ChAT-Cre:TASK ${ }^{f / f}$ and wild-type (WT) mice, we recorded electrocortical activity while simultaneously microperfusing histamine locally into the basal forebrain.

\section{Materials and Methods}

All procedures in the freely behaving mice were performed in accordance with the guidelines of the Canadian Council on Animal Care and were approved by the University of Toronto Animal Care Committee.

In vitro studies. HEK 293 cells were maintained in DMEM/F-12 medium/nutrient mixture containing $10 \% \mathrm{FBS}$, penicillin $(100 \mathrm{U} / \mathrm{ml})$, and streptomycin $(100 \mu \mathrm{g} / \mathrm{ml})$ and cotransfected with TASK channel constructs (Talley and Bayliss, 2002), the $\mathrm{H}_{1}$ receptor (Carrillo et al., 2003), and a GFP reporter using LipofectAMINE 2000 (Invitrogen). Cells were plated onto poly-L-lysine $(100 \mu \mathrm{g} / \mathrm{ml})$-coated glass coverslips $\sim 12-16 \mathrm{~h}$ after transfection and allowed to adhere for $30-40 \mathrm{~min}$ at $37^{\circ} \mathrm{C}$ before recording. Cells were visualized under infrared differential interference contrast and epifluorescent optics, and individual transfected cells with green fluorescence were selected for recording.

Whole-cell recordings were obtained at room temperature $\left(20^{\circ} \mathrm{C}\right)$ using 3-5 $\mathrm{M} \Omega$ patch pipettes and an Axopatch $200 \mathrm{~A}$ amplifier in a bath solution consisting of the following (in $\mathrm{mm}$ ): $130 \mathrm{NaCl}, 3 \mathrm{KCl}, 2 \mathrm{MgCl}_{2}$, $2 \mathrm{CaCl}_{2}, 10$ HEPES, 10 glucose, with $\mathrm{pH}$ adjusted using $\mathrm{NaOH}$ or $\mathrm{HCl}$. Internal solution contained the following (in $\mathrm{mM}$ ): $120 \mathrm{KCH}_{3} \mathrm{SO}_{3}, 4$ $\mathrm{NaCl}, 1 \mathrm{MgCl}_{2}, 0.5 \mathrm{CaCl}_{2}$, 10 HEPES, 10 EGTA, $3 \mathrm{MgATP}$, 0.3 GTP-Tris, with $\mathrm{pH}$ adjusted to 7.2. Voltage commands were applied, and currents were recorded and analyzed with pClamp software (Molecular Devices). Cells were held at $-60 \mathrm{mV}$, and depolarizing ramps $(0.2 \mathrm{~V} / \mathrm{s}$, from -130 to $20 \mathrm{mV}$ ) were applied at $5 \mathrm{~s}$ intervals to generate current-voltage ( $I-V)$ curves. The bath was acidified to $\mathrm{pH} 5.9$ from $\mathrm{pH} 7.3$ or $\mathrm{pH} 8.4$, and histamine was added at $20 \mu \mathrm{M}$. The current required to maintain the membrane at the holding potential $(-60 \mathrm{mV})$ was measured, and the slope conductance was determined by linear fits to currents from -130 to $-60 \mathrm{mV}$. The effect of histamine was normalized to the $\mathrm{pH}$-sensitive conductance for each cell and then averaged.

The in vitro studies investigated the action of $\mathrm{H}_{1}$ receptors on TASK channel currents because, although histamine can activate both $\mathrm{H}_{1}$ and $\mathrm{H}_{2}$ receptors on basal forebrain cholinergic neurons, the increased firing rate and membrane depolarization are primarily due to $\mathrm{H}_{1}$ receptor activation with the contribution of $\mathrm{H}_{2}$ receptors being minimal (Khateb et al., 1995).

In vivo studies. Experiments were performed on 20 male knock-out (KO) mice and 20 male WT mice that were 3-6 months old and between 25 and $35 \mathrm{~g}$. Before the experiment, littermates were housed in cages with controlled temperature $\left(21^{\circ} \mathrm{C}\right)$, lighting (lights on $0700-1900 \mathrm{~h}$ ), and filtered air, as well as ad libitum access to food and water.

Cholinergic cell-specific TASK channel KO mice. Cholinergic neuronspecific TASK channel KO mice (i.e., ChAT-Cre:TASK ${ }^{f / f}$ mice) were generated as previously described (Lazarenko et al., 2010). Briefly, mice with floxed TASK-1 and TASK-3 genes on a C57BL/6J background were crossed with ChAT-IRES-Cre knock-in mice (stock \#006410, The Jackson Laboratory) in which Cre-recombinase expression is from the ChAT locus. ChAT-Cre:TASK ${ }^{f / f}$ mice lack expression of the TASK-1 and TASK-3 genes selectively in cholinergic neurons, including cholinergic neurons of the basal forebrain (Lazarenko et al., 2010) where such channels are normally highly expressed (Marinc et al., 2011). Chat-IRES-Cre mice on a C57BL/6J background (ChAT-Cre:TASK ${ }^{+/+}$) served as WTs. All of the mice studied were also crossed with a line in which mTomato fluorescent protein was expressed from the Rosa26 locus under control of Cre recombinase (stock \#007909, The Jackson Laboratory), to allow visual identification of cholinergic neurons based on mTomato fluorescence. Mice were genotyped as previously described (Lazarenko et al., 2010). Briefly, DNA extracted from tail samples was amplified using multiplex PCR to establish TASK, Cre, and mTomato genotypes.

Preparation for in vivo recordings. Sterile surgery was performed as previously described (Mesbah-Oskui et al., 2014). Briefly, following exposure of the skull by a midline scalp incision, a microdialysis guide cannula (CXG-6, Eicom) was slowly lowered unilaterally using a dorsal approach and stereotaxically positioned $2.5 \mathrm{~mm}$ above the left basal forebrain $(0.14 \mathrm{~mm}$ anterior to bregma, $1.25 \mathrm{~mm}$ lateral to the midline, and $3.25 \mathrm{~mm}$ ventral to bregma). This guide cannula was situated above the target site and was later used to guide a microdialysis probe to the cortically projecting cholinergic neurons of the basal forebrain (Oh et al., 2014), a population delineated by the basal substantia innominata, nucleus of the horizontal limb of the diagonal band, and the magnocellular preoptic nucleus in the mouse brain atlas (Franklin and Paxinos, 1997). Subsequent imaging of cholinergic neurons confirmed the accuracy of the coordinates for microdialysis probe placement (see Results). In addition, electroencephalogram (EEG) screws (0096-3/32, HRS Scientific) were implanted above the frontal and parietal cortices, and electromyogram (EMG) electrodes were implanted into the dorsal neck musculature (AS 631, Cooner Wire) as previously described (Mesbah-Oskui et al., 2014). Mice recovered for at least 1 week before the start of the habituation protocol.

Habituation. Before the microdialysis experiments, the mice were habituated to the conditions inside the recording chamber, especially of attachment to the recording cable (Tang et al., 2004). The habituation protocol consisted of bringing the mice into the recording chamber $48 \mathrm{~h}$ before the experiments and attaching their headpiece to the lightweight counterbalanced recording cable. Mice were able to freely explore their 
environment while attached to the recording cable and remained continuously attached to the cable throughout the habituation and experimental periods.

Recordings were performed in a custom-built, noise-attenuated chamber that was continuously ventilated with room air. The chamber housed a Plexiglas bowl filled with fresh bedding on a rotating turntable (Raturn Sampling Caging System, BASi). The rotating turntable automatically adjusted its position upon movement of the mouse to avoid tangling of the recording cable and microdialysis tubing. Inside the chamber, the mice were exposed to the same $24 \mathrm{~h}$ light-dark cycle that they previously experienced in the animal facility (i.e., lights on 0700$1900 \mathrm{~h}$ ), and also had ad libitum access to food and water. A video camera inside the chamber permitted continuous monitoring of mouse behavior.

Microperfusion of histamine into the basal forebrain. To investigate the role of TASK channels in the histamine-basal forebrain cortical arousal circuit, $1 \mathrm{~mm}$ histamine (Tocris Bioscience) was prepared in aCSF and microperfused into the basal forebrain in $12 \mathrm{WT}$ mice and 12 ChAT-Cre: $\mathrm{TASK}^{\mathrm{f} / f}$ mice. Microperfusion of $1 \mathrm{~mm}$ histamine into the basal forebrain of rats has been shown to promote wakefulness and elicit electrocortical signatures associated with arousal (Ramesh et al., 2004; Zant et al., 2012), but the ion channels involved in histamine action were not determined. It is important to note that the properties of the diffusion membrane lead to delivery of only $\sim 10 \%-20 \%$ of the perfusate concentration (Portas et al., 1996; Grace et al., 2014b) such that tissue concentrations can be expected to be $\sim 100-200 \mu \mathrm{M}$. The concentration of histamine used in HEK cells in vitro $(20 \mu \mathrm{M})$ and the estimated delivery concentration by reverse microdialysis in vivo $(100-200 \mu \mathrm{M})$ are comparable with histamine concentrations $(10-100 \mu \mathrm{M})$ that have been previously shown to evoke responses in basal forebrain cholinergic neurons in slice recordings in vitro (Khateb et al., 1995). We have found that in vivo microperfusion of drugs into brain tissue requires a dose $\sim 10 \times$ those used to produce comparable effects in vitro (Morrison et al., 2002; Morrison et al., 2003; Sood et al., 2003; Liu et al., 2005). Accordingly, the dose of histamine used in the in vivo studies was calculated so that $\sim 10 \times$ the amount used in HEK cells in vitro would be delivered into the tissue.

In the evening before the experimental day, mice were gently restrained and the microdialysis probe (CX-I-8-005, Eicom) was lowered into the guide cannula. The microdialysis probe projected ventrally 2.5 $\mathrm{mm}$ from the tip of the guide to target the basal forebrain. The membrane tip of the microdialysis probe was $0.5 \mathrm{~mm}$ long and $0.22 \mathrm{~mm}$ wide, with a molecular weight cutoff of 50,000 Da. The probe was continuously microperfused overnight with aCSF at a flow rate of $0.5 \mu \mathrm{l} / \mathrm{min}$. Consistent with previous in vivo experiments (Grace et al., 2014a; MesbahOskui et al., 2014), the composition of aCSF was as follows (in mM): 125 $\mathrm{NaCl}, 3 \mathrm{KCl}, 2 \mathrm{CaCl}_{2}, 1 \mathrm{MgSO}_{4}, 25 \mathrm{NaHCO}_{3}$, and 30 D-glucose. The aCSF solution was bubbled with $\mathrm{CO}_{2}$ to a $\mathrm{pH}$ of 7.4 and warmed to $37^{\circ} \mathrm{C}$.

On the day of the experimental recording, the flow rate was increased to $3 \mu \mathrm{l} / \mathrm{min}$ and EEG and EMG signals were recorded. The basal forebrain was microperfused with aCSF from $\sim 0930$ to $1200 \mathrm{~h}$. At $1200 \mathrm{~h}$, the perfusate was switched to $1 \mathrm{~mm}$ histamine (dissolved in aCSF) and maintained until $1500 \mathrm{~h}$. Data obtained in the first $30 \mathrm{~min}$ after switching to histamine (i.e., 1200-1230 h) were excluded from analyses to allow time for histamine to pass through the tubing and diffuse into the tissue. The entire experimental protocol occurred over a $6 \mathrm{~h}$ period during the time of day when the mice normally sleep.

In a separate study, $8 \mathrm{WT}$ mice and $8 \mathrm{ChAT}$-Cre:TASK ${ }^{f / f}$ mice received continuous microperfusion of aCSF into the basal forebrain for the entire experimental period (i.e., serving as a time-control group). This additional protocol was used to control for any potential time of day influences on sleep-wake state and electrocortical activity.

Histological verification of sites of microperfusion into basal forebrain. Following completion of the microdialysis experiments, the mice were killed by $5 \%$ isoflurane and then transcardially perfused with $0.9 \%$ saline followed by a $10 \%$ formalin solution. To verify the location of the probe lesion, the brain was then removed, immersion fixed, and sectioned as described previously (Montandon et al., 2011).

Briefly, the brain was immersion-fixed in $10 \%$ formalin solution for $2 \mathrm{~d}$. Brains were then transferred to a $30 \%$ sucrose solution for at least $2 \mathrm{~d}$ and stored at $4^{\circ} \mathrm{C}$. Using a cryostat and microtome (Leica, CM 1850), brains were frozen at $-20^{\circ} \mathrm{C}$ and coronally sectioned across the span of the basal forebrain in $50 \mu \mathrm{m}$ slices. The sections were then mounted on glass slides and dried overnight. To visualize cell bodies, Neutral Red staining was performed the following day, and the slides sealed were with Cytoseal 280 (Thermo Scientific) under glass coverslips. The location of the probe lesion was verified through imaging of the stained sections using a CCD camera and microscope (Infinity 1 and BX-41, Olympus) and the Infinity Capture software package (Lumenera). Recordings collected from mice in which the probe lesion was located outside of the basal forebrain (Franklin and Paxinos, 1997) were not analyzed.

Confocal imaging of mTomato ${ }^{+}$cholinergic neurons in the basal forebrain. The anatomical location of cholinergic neurons in the basal forebrain was mapped using confocal microscopy to visualize the mTomato fluorescent protein. Imaging was performed using a $543 \mathrm{~nm}$ laser on the $5 \times$ objective (Leica TCS-SL, Leica Microsystems). $Z$-stack images were acquired at $5 \mu \mathrm{m}$ intervals through the $50-\mu \mathrm{m}$-thick sections. The $z$-series images were then processed in ImageJ (Schneider et al., 2012) using the Bio-Formats LOCI (Linkert et al., 2010) and the "Sum Slices" $Z$-projection function. Images of microscope fields from the same section were then stitched together without further processing using Adobe Photoshop (Adobe Systems).

Data acquisition. EEG and EMG signals were amplified and filtered (Super-Z headstage amplifiers and BMA-400 amplifiers/filters, CWE) before being digitized (CED Micro1401, CED) and saved using Spike 2 software (CED). EEG signals were amplified 5000 times, filtered between 1 and $100 \mathrm{~Hz}$, and digitized at $1000 \mathrm{~Hz}$. EMG signals were amplified 2000 times, filtered between 100 and $1000 \mathrm{~Hz}$, and digitized at $2000 \mathrm{~Hz}$.

EEG scoring and analysis. The effect of histamine microperfused into the basal forebrain on electrocortical activity was assessed across the different sleep-wake states. To this end, the EEG and EMG recordings were first visually scored using standard criteria and $5 \mathrm{~s}$ epochs (Grace et al., 2014a; Mesbah-Oskui et al., 2014). Each epoch was assigned to wakefulness, non-rapid eye movement (NREM) sleep, or rapid eye movement (REM) sleep.

The activity of histaminergic tuberomamillary neurons is highly correlated with periods of high vigilance and motor activity (Takahashi et al., 2006); and during wakefulness, basal forebrain neurons fire maximally during movements (Szymusiak et al., 2000). Accordingly, epochs of wakefulness were further divided into quiet wakefulness and active wakefulness. For each recording period, wakefulness epochs with overt and sustained EMG activity exceeding 25\% of the maximum recorded EMG signal were scored as active wakefulness. After scoring, the root mean squared EMG activity was quantified for each state using MATLAB (version R2013a, The MathWorks, function: rms) to further validate the scoring of quiet wakefulness and active wakefulness. The amount of time spent in each sleep-wake state was calculated for each animal as a percentage of the total recording time in each treatment (i.e., aCSF or histamine).

Electrocortical activity during each sleep-wake state was analyzed as previously described (Mesbah-Oskui et al., 2014). Briefly, a fast Fourier transform (size 1024, script SUDSA22, Spike2 software, CED) was used upon overlapping 512 sample segments and windowed using the Hann function, which generated power spectra for each epoch. The spectral composition of each $5 \mathrm{~s}$ epoch was analyzed using five bandwidths: $1-4$ $\mathrm{Hz}(\delta), 4-8 \mathrm{~Hz}(\theta), 8-12 \mathrm{~Hz}(\alpha), 12-30 \mathrm{~Hz}(\beta)$, and $30-50 \mathrm{~Hz}(\gamma)$. The raw EEG power $\left(\right.$ in $\mathrm{V}^{2}$ ) was also obtained. Subsequently, each frequency band was then normalized to the total power $(1-50 \mathrm{~Hz})$ of the $5 \mathrm{~s}$ epoch to obtain the percentage total power.

All epochs in a specific treatment group (i.e., microperfusion of aCSF or histamine into the basal forebrain) and for each sleep-wake state (i.e., quiet wakefulness, active wakefulness, NREM sleep, and REM sleep) were then averaged for each frequency band in each animal. The data for each animal were then grouped according to genotype (i.e., WTs or ChAT-Cre:TASK ${ }^{f / f} \mathrm{KO}$ mice).

Analysis is performed a priori on the EEG signal normalized to the total power (Mesbah-Oskui et al., 2014) to reduce the inherent variability that arises in measures of absolute EEG power between mice, for example, due to variation in the depth of electrode placement, local differences 

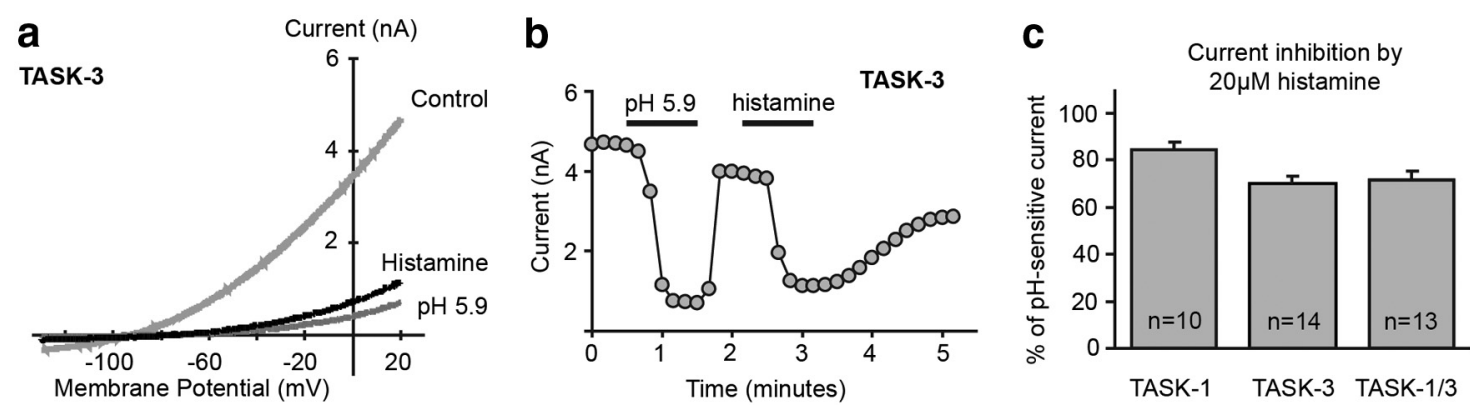

Figure 1. Histamine inhibits TASK currents in vitro. $a, I-V$ plot of $\mathrm{K}^{+}$leak currents in a HEK 293 cell transfected with the $\mathrm{H}_{1}$ receptor and TASK-3 channel. A control trace depicting the "leak" $\mathrm{K}^{+}$ current at rest is shown (light gray trace); the current was inhibited by bath acidification (to pH 5.9, dark gray trace) or application of $20 \mu \mathrm{m} \mathrm{histamine} \mathrm{(black} \mathrm{trace).} \boldsymbol{b}$, Time series illustrating the effect on peak current (at $20 \mathrm{mV}$ ) of bath acidification and histamine (from the cell in $\boldsymbol{a}$ ). $\boldsymbol{c}$, Group data depicting the percentage of the $\mathrm{pH}$-sensitive ${ }^{+}$leak current inhibited by bath application of $20 \mu \mathrm{m}$ histamine in HEK cells expressing TASK-1, TASK-3, or TASK-1/3 channels. The numbers indicate the number of cells recorded in each group.

in tissue swelling, and recovery, etc. Relative changes between the aCSF and histamine conditions were also compared between the WT and ChAT-Cre:TASK ${ }^{f / f}$ mice as percentage change. This normalization also allows for any consistent effect of the intervention between groups to be identified (Mesbah-Oskui et al., 2014).

Statistical analysis. The effect on sleep-wake architecture and electrocortical activity elicited by (1) microperfusion of histamine into the basal forebrain or (2) TASK gene KO was assessed using a two-way repeatedmeasures ANOVA. We tested for the effect of drug treatment (i.e., aCSF vs histamine) and genotype (i.e., WT vs ChAT-Cre:TASK ${ }^{f / f}$ mice). Comparison of variables during baseline microperfusion of aCSF into the basal forebrain also tested for potential effects of genotype on electrocortical activity in the different frequency bands and sleep-wake architecture. Bonferroni corrected $p$ values were used in post hoc comparisons. For comparison of neck EMG activity across sleep-wake states, the data were analyzed using repeated-measures ANOVA. All analyses were performed using SigmaStat software (SPSS). Data are presented as the mean \pm SEM. Differences were considered statistically significant if $p<$ 0.05 .

\section{Results}

Histamine inhibits TASK currents in vitro

HEK 293 cells transfected with $\mathrm{H}_{1}$ receptors and TASK-3 channels displayed a $\mathrm{pH}$-sensitive $\mathrm{K}^{+}$current that was inhibited by histamine (Fig. 1a,b). The histamine-induced inhibition at $\mathrm{pH}$ 7.3 accounted for $\sim 70 \%-80 \%$ of the $\mathrm{K}^{+}$current blocked by bath acidification (to $\mathrm{pH}$ 5.9) in these transfected cells and was observed with TASK-1, TASK-3, and heterodimeric TASK-1/3 channels (Fig. 1c). Currents from heterodimeric TASK-1/3 channels were enhanced in a bath solution alkalized to $\mathrm{pH}$ 8.4. Under these conditions, histamine inhibited $71.7 \pm 2.2 \%(n=10)$ of the $\mathrm{pH}$-sensitive current (from $\mathrm{pH} 8.4$ to $\mathrm{pH} 5.9$ ), essentially identical to the fraction inhibited at $\mathrm{pH} 7.3(71.8 \pm 3.6 \%, n=13, p>$ 0.99 , unpaired $t$ test). These data identify modulation of TASK channels as a mechanism of histamine action, in agreement with observations from brain slice preparations showing that histamine can inhibit $\mathrm{K}^{+}$leak currents (McCormick and Williamson, 1991; Reiner and Kamondi, 1994; Li and Hatton, 1996).

To next identify the relevance of TASK channels as a target of histamine signaling in a cortical arousal circuit, we performed additional studies in freely behaving mice in vivo.

\section{Microperfusion of histamine into the basal forebrain of mice} lacking TASK-1/3 channels selectively in cholinergic neurons Figure 2 shows an example of a histological section from a single mouse illustrating the location of a microdialysis probe in the basal forebrain (Fig. 2a). The locations of the microdialysis probes in all of the mice used in the histamine study $(n=24)$ and the time-control experiments $(n=16)$ are illustrated on standard cross-sections from the mouse brain atlas (Fig. $2 b$; multiple dialysis sites overlap, indicating consistency in placement). The probes were successfully implanted into the basal forebrain in all of the mice analyzed.

Figure $2 b$ also shows the location of mTomato-positive neurons in sections from a single animal across the basal forebrain matched to the corresponding sections from the mouse brain atlas. The location of cholinergic neurons is indicated by ChAT and cre-dependent expression of mTomato fluorescent protein. Higher-magnification images are shown in Figure $2 c$. These mTomato-positive cholinergic neurons express cre-recombinase linked to the ChAT promoter. It is in these basal forebrain neurons, and other cholinergic neurons elsewhere in the brain, that TASK- $1 / 3$ channels are absent in the $\mathrm{KO}$ mice but are normally expressed in the WTs as has been previously shown (Lazarenko et al., 2010).

Figure $2 d$ illustrates representative gels from multiplex PCR and shows the genetic profile of the KO and WT mice. Figure $2 e$ shows the protocol for microperfusion of histamine into the region of the basal forebrain containing cholinergic neurons with or without TASK-1/3 channels. Figure $2 e$ also shows the protocol for the time-control experiments in both the KO and WT mice.

\section{Electrophysiological recordings in freely behaving mice}

Figure $3 a$ shows an example of the EEG and neck EMG signals recorded in one mouse across sleep-wake states. The average continuous EEG power spectra are also shown for each sleepwake state during microperfusion of aCSF into the basal forebrain in the WT mice (Fig. 3b). Note, for example, the higher slow-frequency power in NREM sleep compared with wakefulness and REM sleep. Also note the relatively higher $\theta$ power in REM sleep compared with the other states. Motor activity, as quantified from the neck EMG, also varied significantly across sleep-wake states (Fig. $3 c ; p<0.001$, one-way repeated-measures ANOVA) with significant differences between all pairs of states, except NREM and REM sleep (Fig. $3 c$; each $p<0.05$, post hoc paired $t$ tests).

TASK channel deletion on cholinergic neurons alters electrocortical activity but not sleep-wake architecture or motor activity

Electrocortical activity

First, we identified whether TASK channel deletion on cholinergic neurons alters baseline electrocortical activity. Figure $4 a$ shows the percentage of the total EEG power separated into the 


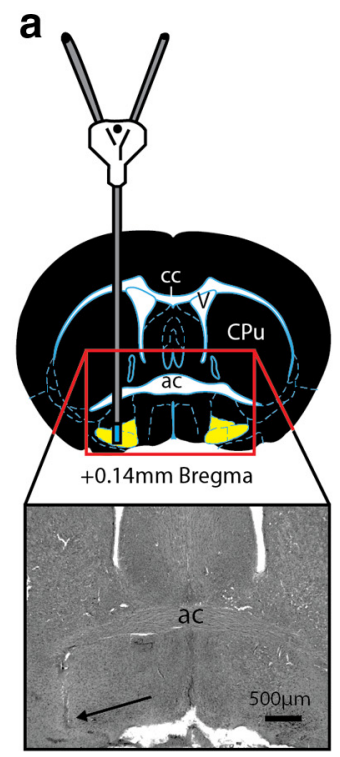

$-0.34$

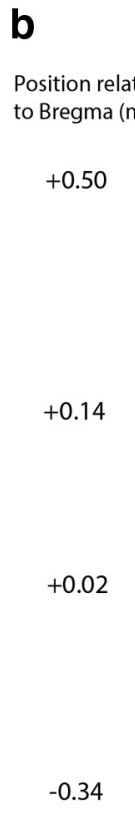

d

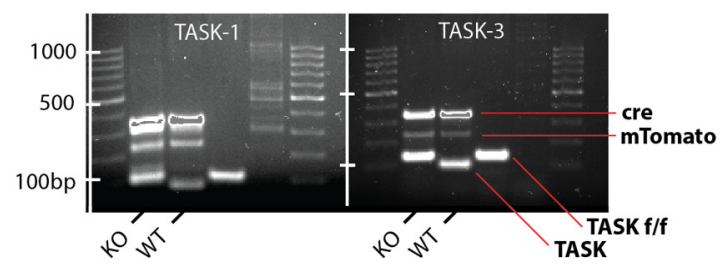

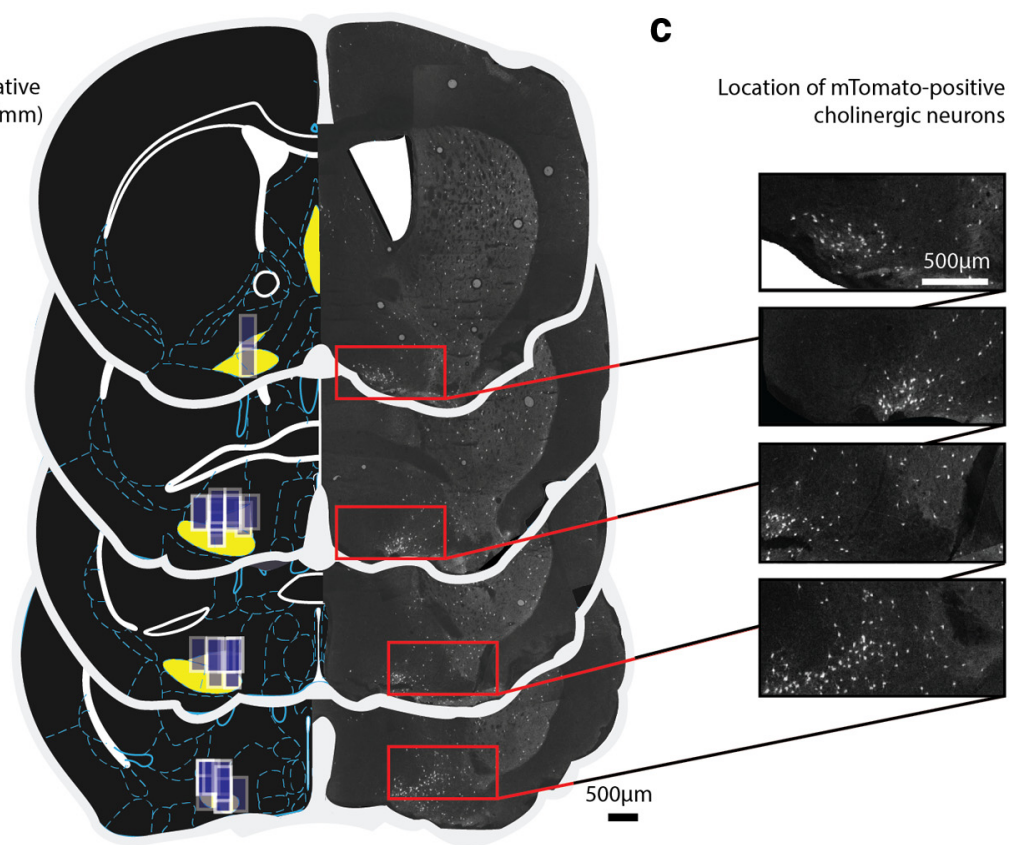

e

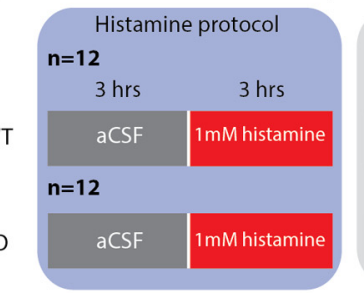

Microperfusion

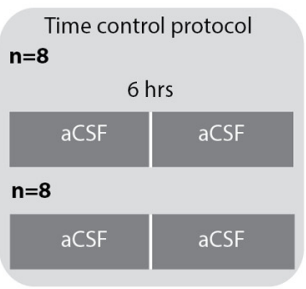

Figure 2. Microperfusion of histamine into the basal forebrain of mice lacking TASK-1/3 channels in cholinergic neurons. $\boldsymbol{a}$, Schema illustrating the location of a microdialysis probe in the basal forebrain. Inset, Histological section from a single animal and the location of the tip of the microdialysis membrane (black arrow). $\boldsymbol{b}$, Microdialysis probe locations in all mice used in the study are depicted as translucent blue rectangles (drawn to scale) along the span of the basal forebrain on standard cross sections from the mouse brain atlas (Franklin and Paxinos, 1997). Multiple dialysis sites overlap, indicating consistency in placement. Cholinergic basal forebrain neurons encompass the area defined by the basal substantia innominata, magnocellular preoptic nucleus, the nucleus of the horizontal limb of the diagonal band, and the medial septum (together depicted as the yellow region on each section). The basal forebrain sections from the brain atlas are paired with confocal images of histological sections from ChAT-Cre:TASK ${ }^{f / f}$ mice expressing mTomato fluorescent protein on ChAT ${ }^{+}$neurons. c, Magnification of the confocal images depicts the mTomato-positive cholinergic neurons. The location of these neurons corresponds to the region of the basal forebrain that was targeted by the microdialysis probes. $\boldsymbol{d}$, Genetic profile of ChAT-Cre:TASK ${ }^{f / f}$ (KO) and ChAT-Cre:TASK ${ }^{+/+}$(WT) mice, as well as an additional strain not used in experiments (i.e., floxed TASK-1/3 without cre expression). e, Microperfusion protocol in the histamine and time control groups, with four experimental groups in total. The number of WT and K0 animals used are shown, as well as the duration of microperfusion into the basal forebrain of aCSF or histamine (1 mm). Scale bars, $500 \mu \mathrm{m}$. cc, Corpus callosum; ac, anterior commissure; CPu, caudate-putamen.

different frequency bands for all of the mice recorded during microperfusion of aCSF into the basal forebrain (i.e., the baseline control condition). Data are shown for both WT mice and ChATCre:TASK ${ }^{f f f}$ mice lacking TASK-1/3 channels in cholinergic neurons $(n=20$ for each group because the initial baseline aCSF control condition was the same for the 12 mice in the histamine protocol and the 8 mice in the time control protocol; for reference, see Fig. 2e).

Statistical analyses showed that TASK-1/3 channels on cholinergic neurons contribute to baseline electrocortical activity. Analysis of the group data in NREM sleep showed that there was a significant difference in the percentage of the total EEG power in different frequency bands that depended on genotype (significant interaction between genotype and frequency band, $F_{(4,190)}=2.69$, $p=0.033$, two-way repeated-measures ANOVA). Further analysis identified that $4-8 \mathrm{~Hz}$ EEG power was significantly higher in the ChAT-Cre:TASK ${ }^{f / f}$ mice compared with the WTs (Fig. $4 a ; p=$ 0.011 , post hoc paired $t$ test).

In quiet wakefulness, there was also a significant difference in the different EEG frequency bands that depended on genotype (significant interaction between genotype and frequency band,
$F_{(4,190)}=5.72, p<0.001$, two-way repeated-measures ANOVA). In quiet wakefulness, as in NREM sleep, $4-8 \mathrm{~Hz}$ EEG power was significantly higher in the ChAT-Cre:TASK ${ }^{f / f}$ mice compared with the WTs (Fig. $4 a ; p=0.026$, post hoc paired $t$ test). Also, $1-4$ $\mathrm{Hz}$ and $30-50 \mathrm{~Hz}$ EEG power was significantly lower in the ChAT-Cre:TASK ${ }^{f / f}$ mice compared with WTs (Fig. $4 a ; p=0.005$ and $p=0.023$, post hoc paired $t$ tests).

Likewise, in REM sleep, there was a significant difference in the different EEG frequency bands that was dependent on genotype (significant interaction between genotype and frequency band, $F_{(4,190)}=2.55, p=0.041$, two-way repeated-measures ANOVA). Post hoc analyses identified that $12-30 \mathrm{~Hz}$ EEG power was significantly higher in the ChAT-Cre:TASK ${ }^{f / f}$ mice compared with the WTs (Fig. $4 a ; p=0.028$, post hoc paired $t$ test).

\section{Total EEG power and sleep-wake architecture}

The data described above show that KO of TASK- $1 / 3$ channels on cholinergic neurons leads to alterations in specific EEG frequency bands within particular sleep-wake states. This effect on EEG network activity shown in Figure $4 a$ occurred without alterations in global electrocortical activity as judged by total EEG power 
(Fig. 4b) and without changes in sleepwake architecture (Fig. 4c). Statistical analysis confirmed that there was no effect of genotype on the total EEG power for each sleep-wake state $\left(F_{(3,152)}=0.734\right.$, $p=0.533$, two-way repeated-measures ANOVA), nor was there any effect of genotype on the percentage of time spent in each sleep-wake state $\left(F_{(3,152)}=0.163\right.$, $p=0.921$, two-way repeated-measures ANOVA).

\section{Neck EMG activity}

There was no effect of genotype on neck EMG activity recorded across sleep-wake states $\left(F_{(3,111)}=1.33, p=0.269\right.$, two-way repeated-measures ANOVA).

\section{Histamine at the basal forebrain promotes cortical arousal in vivo} Before identifying the role of TASK-1/3 channels on cholinergic neurons in mediating the effects of histamine on electrocortical activity in freely behaving mice in vivo, we first needed to identify that microperfusion of histamine into the basal forebrain promotes cortical arousal per se.

\section{Sleep-wake architecture}

Figure $5 a$ shows that microperfusion of histamine into the basal forebrain was sufficient to cause a significant change in the time spent in the different sleep-wake states. Histamine at the basal forebrain decreased the percentage of time spent in NREM sleep and caused a reciprocal increase in the percentage of time spent in quiet wakefulness (both $p \leq 0.003$, post hoc paired $t$ tests performed after initial identification of a significant effect of drug treatment from two-way repeated-measures ANOVA: both $F_{(1,22)}>8.97$, both $\left.p<0.008\right)$.

Histamine at the basal forebrain increased the percentage of time spent in active wakefulness but only in the mice lacking TASK- $1 / 3$ channels on cholinergic neurons ( $p<0.001$, post hoc paired $t$ test performed after initial identification of a significant effect of drug treatment that depended on genotype from twoway repeated-measures ANOVA: $\left.F_{(1,22)}=8.01, p=0.010\right)$.

There was no effect of histamine at the basal forebrain on the percentage of time spent in REM sleep, and there was no effect of histamine on sleep-wake architecture that depended on genotype (both $F_{(1,20)}<2.73$, each $p>0.113$, two-way repeatedmeasures ANOVA).

We then performed additional analyses on the duration and number of sleep-wake bout lengths with aCSF and histamine to further tease out any possible effects of genotype on the sleepwake architecture (Fig. 5a). The average length of the NREM sleep episodes was reduced by histamine in both the WT and ChAT-Cre:TASK ${ }^{f / f}$ mice $(67.5 \pm 10.5$ to $46.1 \pm 4.3 \mathrm{~s}$ and $57.7 \pm$ 6.4 to $41.0 \pm 5.1 \mathrm{~s}$, respectively, $F_{(1,22)}=13.33, p=0.001$ for the effect of histamine but with no significant effect of genotype, $F_{(1,22)}=0.79, p=0.385$, two-way repeated-measures ANOVA). There was no significant effect of histamine on the number of
NREM bouts per hour in the WT and ChAT-Cre:TASK ${ }^{f / f}$ mice $(26.7 \pm 2.3$ to $29.6 \pm 2.6$ per hour and $31.0 \pm 2.3$ to $27.9 \pm 2.3$ per hour, respectively, $F_{(1,22)}=0.006, p=0.941$ for the effect of histamine, again with no effect of genotype, $F_{(1,22)}=0.19, p=$ 0.666, two-way repeated-measures ANOVA).

Along with the histamine-induced decrease in the time spent in NREM sleep, there was an increase in the time spent in quiet waking. This effect was produced by an increase in the number of bouts of quiet waking per hour $\left(F_{(1,22)}=6.86, p=0.016\right.$, two-way repeated-measures ANOVA) but not their duration $\left(F_{(1,22)}=2.55\right.$, $p=0.124)$, again with no effect of genotype (each $F_{(1,22)}<3.66$, $p>0.068$, two-way repeated-measures ANOVA). The significant increase in the overall time spent in active wakefulness induced by histamine in the ChAT-Cre:TASK ${ }^{f / f}$ mice (Fig. $5 a$ ) was produced by increases in average bout length (35.0 \pm 3.5 to $40.0 \pm$ $2.5 \mathrm{~s})$ and their frequency $(20.7 \pm 2.8$ to $24.8 \pm 3.2$ per hour $)$, although neither alone reached statistical significance (each $F_{(1,22)}<2.35, p>0.140$, two-way repeated-measures ANOVA). This latter result indicated that the overall histamine-induced increase in the time spent in active wakefulness in the ChAT-Cre: $\mathrm{TASK}^{\mathrm{f} / f}$ mice was produced by various combinations of increased bout length and/or frequency in individual mice.

\section{Total EEG power}

Figure $5 b$ shows that microperfusion of histamine into the basal forebrain caused a significant decrease in total EEG power in NREM sleep, quiet wakefulness, and REM sleep (each $F_{(1,20-22)}>$ 
a
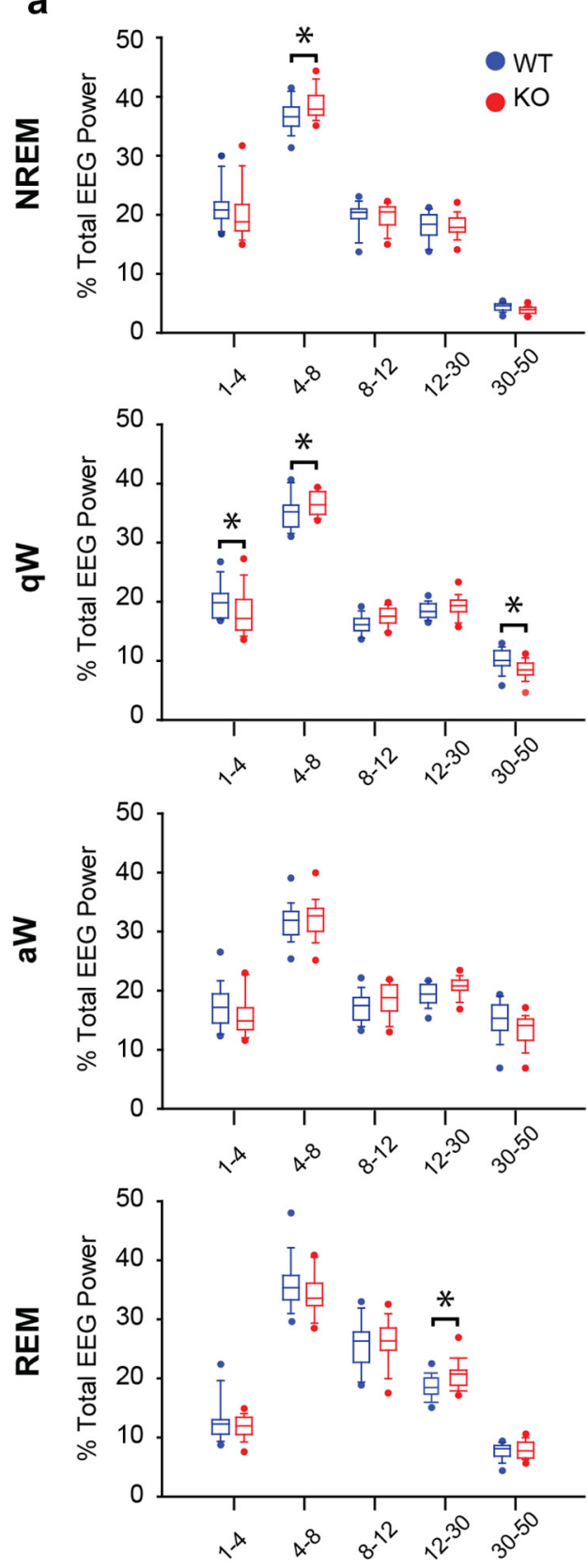

Frequency Bands $(\mathrm{Hz})$

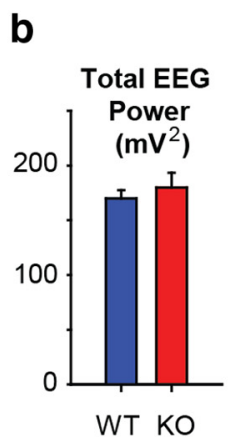

C
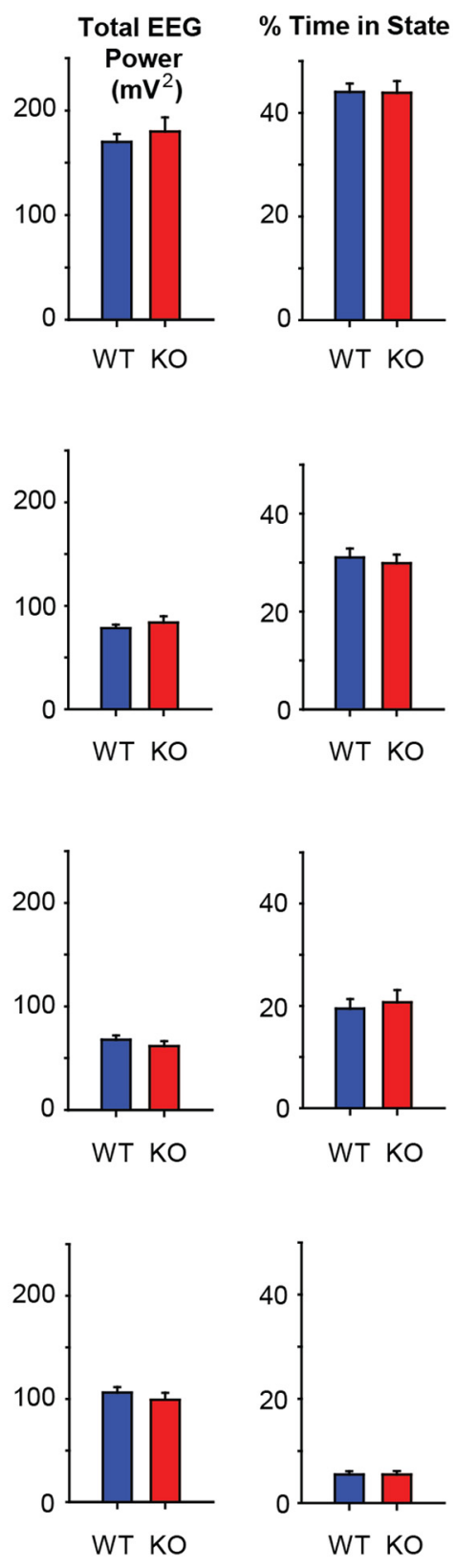

\section{Genotype}

Figure 4. TASK channel deletion on cholinergic neurons alters electrocortical activity but not sleep-wake architecture. $\boldsymbol{a}$ Percentage of total EEG power across sleep-wake states in the different frequency bands for ChAT-Cre:TASK ${ }^{+/+}$(WT, blue) and ChAT-Cre:TASK ${ }^{f / f}$ (KO, red) mice under baseline conditions of aCSF microperfusion into the basal forebrain ( $n=20$ WT and $n=20$ ChAT-(re:TASK ${ }^{f / f}$ mice). In the box-and-whisker plots: Boxes represent the second and third quartiles separated by the median. Bottom and top whiskers represent the 10th and 90 th percentiles, respectively. Individual dot symbols represent the extreme (i.e., highest and lowest) values from animals in each group. Groups were compared using a two-way repeated-measures ANOVA (factors being genotype and frequency band). $\boldsymbol{b}$, Total EEG power (1-50 Hz) in the different sleep-wake states in WT and ChAT-Cre:TASK ${ }^{f / f}$ mice. Values are mean \pm SEM. Groups were compared using a two-way repeated-measures ANOVA (factors being genotype and state). c, Percentage of time spent in the different sleep-wake states in WT and ChAT-Cre:TASK ${ }^{f / f}$ mice. Values are mean \pm SEM. Groups were compared using a two-way repeated-measures ANOVA (factors being genotype and state). ${ }^{*} p<$ 0.05 , significant difference between groups. For further details, see Results.

13.05, each $p \leq 0.002$, two-way repeated-measures ANOVA, with all $p \leq 0.002$ with post hoc paired $t$ tests), indicative of cortical arousal. This overall effect of histamine on total EEG power in these states did not depend on genotype (each $F_{(1,20-22)}<3.64$, each $p>0.07$, two-way repeated-measures ANOVA). In active wakefulness (i.e., when cortical arousal state is already relatively high), there was no effect of microperfusion of histamine into the basal forebrain on total EEG power and also no effect of genotype (both $F_{(1,22)}<2.66$, both $p>0.11$, twoway repeated-measures ANOVA). Figure $5 c$ shows continuous power spectra from representative WT and ChAT-Cre:TASK ${ }^{f / f}$ mice, illustrating the decrease in total EEG power induced by microperfusion of histamine into the basal forebrain. Subsequent analyses of EEG activity were performed on the EEG signal normalized to the total power (for details, see Materials and Methods).

TASK channels on cholinergic neurons contribute to the effects of histamine on electrocortical activity

The 30-50 Hz EEG activity

Analysis of the group data shows that TASK-1/3 channels on cholinergic neurons modulate the effect of histamine at the basal forebrain on $30-50 \mathrm{~Hz}$ (i.e., $\gamma$ ) EEG activity (Fig. 6a).

In NREM sleep, histamine at the basal forebrain increased the percent total EEG power in the $30-50 \mathrm{~Hz}$ frequency band $\left(F_{(1,22)}=77.37, p<0.001\right.$, two-way repeated-measures ANOVA, $p<0.001$, post hoc paired $t$ test), with this effect depending on the presence of TASK-1/3 channels on cholinergic neurons $\left(F_{(1,22)}=\right.$ $5.12, p=0.034$, two-way repeatedmeasures ANOVA). Post hoc analysis identified that, compared with WTs, the increase in $30-50 \mathrm{~Hz}$ EEG activity produced by histamine at the basal forebrain was significantly attenuated in the ChATCre:TASK ${ }^{f / f}$ mice that lack TASK-1/3 channels on cholinergic neurons $(p=$ 0.017, post hoc paired $t$ test; Fig. $6 a$ ).

In quiet wakefulness, histamine at the basal forebrain also increased the percentage of the total EEG power in the 30-50 $\mathrm{Hz}$ frequency band $\left(F_{(1,22)}=19.23, p<\right.$ 0.001 , two-way repeated-measures ANOVA, $p<0.001$, post hoc paired $t$ test; Fig. $6 a)$, but this effect was not significantly affected by genotype $\left(F_{(1,22)}=2.50, p=0.128\right.$, twoway repeated-measures ANOVA).

In active wakefulness, histamine at the basal forebrain likewise increased the percentage of the total EEG power in the $30-50 \mathrm{~Hz}$ frequency band $\left(F_{(1,22)}=7.21\right.$, $p=0.014$, two-way repeated-measures ANOVA, $p=0.014$, post hoc paired $t$ test). This effect of histamine also depended on the presence of TASK-1/3 channels on cholinergic neurons $\left(F_{(1,22)}=4.66, p=0.042\right.$, two-way repeated-measures ANOVA $)$. Post hoc analyses showed that the increase in $30-50 \mathrm{~Hz}$ EEG activity produced by histamine at the basal forebrain in active wakeful- 
ness occurred in the ChAT-Cre:TASK ${ }^{f / f}$ mice ( $p=0.002$, post hoc paired $t$ test; Fig. $6 a)$. This activating effect, however, did not occur in the WT mice where 30-50 $\mathrm{Hz}$ EEG activity was already high in active wakefulness and remained unchanged by histamine ( $p=0.714$, post hoc paired $t$ test).

In REM sleep, histamine at the basal forebrain had no significant effect on the percentage of the total EEG power in the $30-50 \mathrm{~Hz}$ frequency band $\left(F_{(1,20)}=2.94\right.$, $p=0.102$, two-way repeated-measures ANOVA) and was unaffected by genotype $\left(F_{(1,20)}=3.62, p=0.072\right.$, two-way repeated-measures ANOVA).

The continuous frequency plots (Fig. $6 b, c)$ further illustrate that the shift in electrocortical activity is due to histamine and not due to time-of-day effects, as the EEG was not affected in the time-control experiments.

Other frequency bands

Figure 7 shows that microperfusion of histamine into the basal forebrain also influenced EEG activity in other frequency bands. Together with the effects on 30-50 $\mathrm{Hz}$ EEG activity, these data are also consistent with the histamine modulating cortical arousal state and promoting EEG signatures of increased arousal. Overall, there is a histamine-induced shift toward decreased slower frequency EEG activity and increased faster EEG activity.

Histamine significantly decreased the percentage of the total EEG power in the 1-4 Hz frequency band in NREM sleep and quiet waking (each $F_{(1,22)}>15.22, p<0.001$, two-way repeated-measures ANOVA, $p<0.001$, post hoc paired $t$ tests) as well as $4-8 \mathrm{~Hz}$ activity in quiet and active waking (each $F_{(1,22)}>12.56, p \leq 0.002$, two-way repeated-measures ANOVA, $p \leq 0.002$, post hoc paired $t$ tests). Histamine also increased the percentage of the total EEG power in the 8-12 $\mathrm{Hz}$ frequency band in quiet and active waking and increased 12-30 Hz activity in NREM sleep and quiet waking (each $F_{(1,22)}>7.02, p \leq 0.015$, two-way repeated-measures ANOVA, $p \leq 0.015$, post hoc paired $t$ tests).

In REM sleep, the effect of histamine on the percentage of the total EEG power in the $12-30 \mathrm{~Hz}$ frequency band depended on the presence of TASK-1/3 channels on cholinergic neurons $\left(F_{(1,20)}=4.53, p=0.046\right.$, two-way repeated-measures ANOVA). Further analysis showed that the increase in 12-30 Hz EEG activity produced by histamine at the basal forebrain in REM sleep occurred in the WT mice ( $p=0.039$, post hoc paired $t$ test; Fig. 7 ) but not in the ChAT-Cre:TASK ${ }^{f / f}$ mice $(p=0.436$, post hoc paired $t$ test).

Other differences in EEG frequency bands between WT and ChAT-Cre:TASK ${ }^{f / f}$ mice are consistent with the data shown in Figure 4.

\section{Discussion}

Here we show that histamine receptor activation modulates TASK channels in vitro, consistent with previous in vitro studies b Total EEG Power $(1-50 \mathrm{~Hz})$

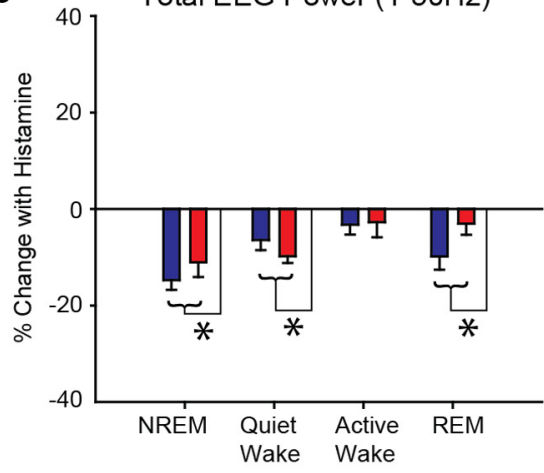

REM

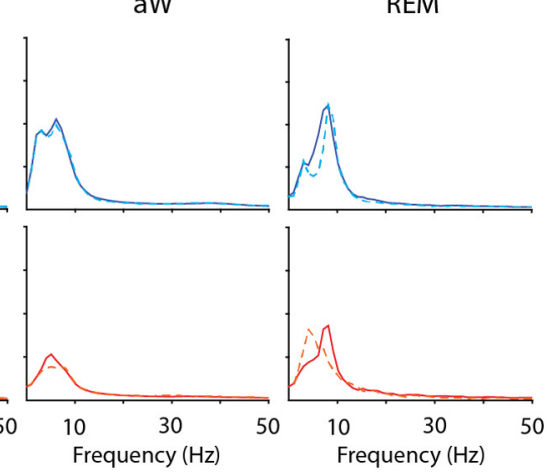

Figure 5. Histamine at the basal forebrain promotes cortical arousal in vivo. $\boldsymbol{a}$, Percentage change in the time spent in each sleep-wake state in WT (blue) and ChAT-Cre:TASK ${ }^{f / f}(K 0$, red) mice with histamine $(1 \mathrm{mM}) \cdot \boldsymbol{b}$, Percent change in total EEG power $(1-50 \mathrm{~Hz})$ in WT and ChAT-Cre:TASK ${ }^{f / f}$ mice across sleep-wake states with histamine. Group sizes were $n=12 \mathrm{WT}$ and $n=12$ (fore ment). $c$, Continuous power spectra for each sleep-wake state from representative WT and ChAT-Cre:TASK ${ }^{f / f}$ mice during microperfusion aCSF and histamine into the basal forebrain. ${ }^{*} p<0.05$, significant effect of drug treatment. ${ }^{\#} p<0.05$, significant interaction between the genotype and treatment effects. Values are mean \pm SEM.

showing that other wakefulness-active neurotransmitters (noradrenaline, serotonin, and orexin) also inhibit TASK currents (Talley et al., 2000; Larkman and Perkins, 2005; Weber et al., 2008; Doroshenko and Renaud, 2009), likely acting through a G $\alpha$ q-mediated mechanism (Chen et al., 2006; Wilke et al., 2014). Our in vitro results linking TASK channels and histamine receptors are consistent with previous in vitro studies showing that histamine suppresses a $\mathrm{K}^{+}$leak conductance (McCormick and Williamson, 1991; Reiner and Kamondi, 1994; Li and Hatton, 1996), although the channels involved were not identified in those previous studies. To our knowledge, this is the first identification of such a histamine-TASK channel mechanism.

We then show, in vivo, that TASK channels on cholinergic neurons contribute to endogenous EEG oscillations as well as the arousal effects of histamine in the $\gamma$ frequency band. Although a previous study found that global TASK-3 KO mice lacked a halothane-induced $\theta$ oscillation in vivo (Pang et al., 2009), the present study is the first to test the role of TASK channels within a specific cell group (i.e., cholinergic neurons) in modulating electrocortical activity in vivo. Overall, our findings identify a role for TASK channels on cholinergic neurons in modulating endogenous EEG oscillations, and for TASK channels on basal forebrain cholinergic neurons in modulating the EEG response to histamine at the basal forebrain.

\section{TASK channels and EEG oscillations}

As mediators of a $\mathrm{K}^{+}$leak current that regulates neuronal excitability (Enyedi and Czirják, 2010), TASK channels are involved in 
a
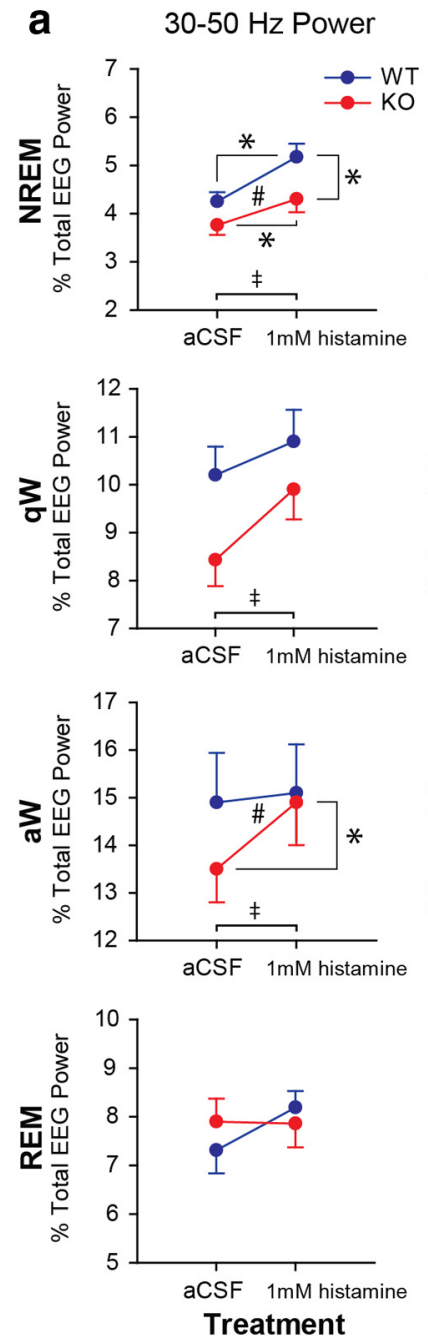

b
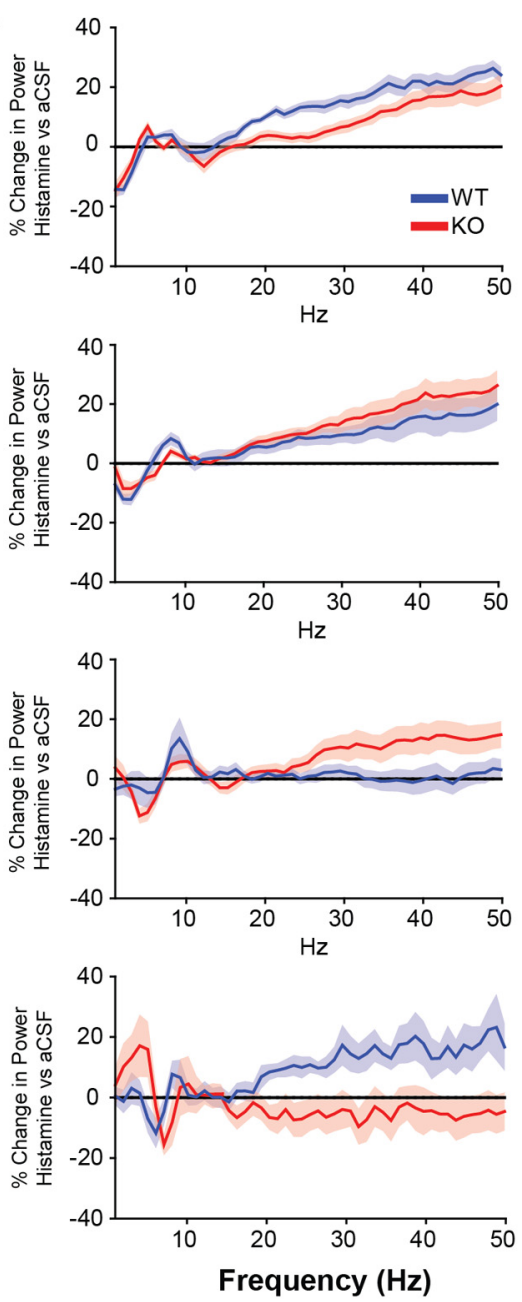

C

aCSF Time Control
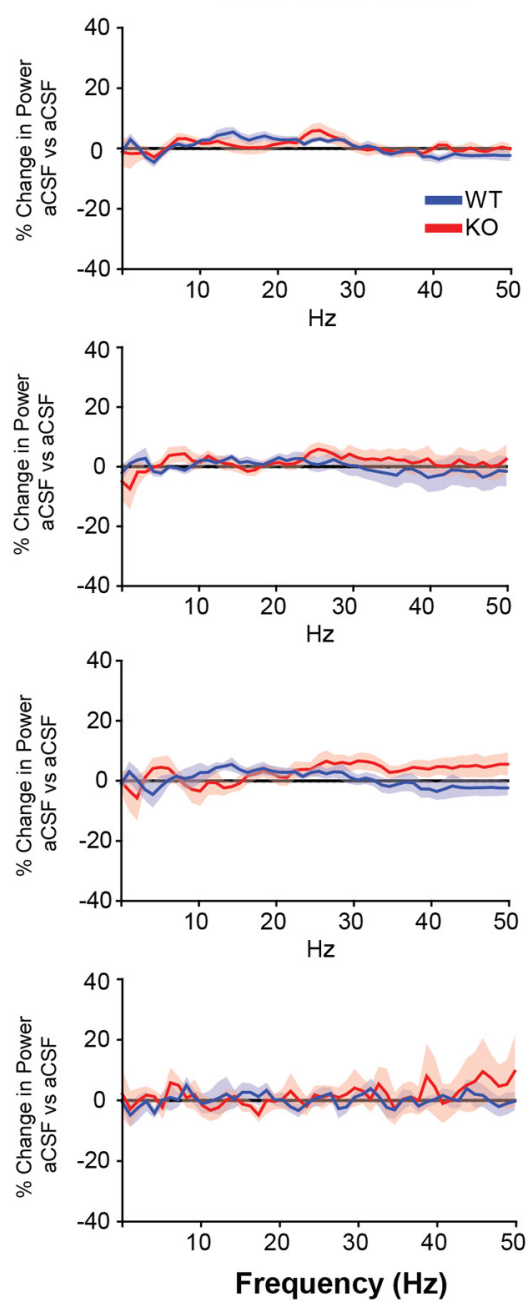

Figure 6. TASK channels on cholinergic neurons contribute to the effects of histamine on electrocortical activity. $\boldsymbol{a}$, Percentage of the total EEG power in the $30-50 \mathrm{~Hz}$ frequency band across the states of NREM sleep, quiet wakefulness (qW), active wakefulness (aW), and REM sleep. The change in 30-50 Hz EEG power from aCSF to $1 \mathrm{~mm}$ histamine treatment for WT (blue) and ChAT-Cre:TASK ${ }^{f f f}$ (KO, red) mice is shown. Histamine promotes $30-50 \mathrm{~Hz}$ EEG power in WT mice, and this effect was significantly modulated by sleep-wake state in ChAT-Cre:TASK ${ }^{f / f}$ mice. $\neq p<$ 0.05 , significant effect of histamine versus aCSF treatment. ${ }^{\#} p<0.05$, significant interaction between genotype and the effect of the perfusion medium. ${ }^{*} p<0.05$, significant difference between groups using a post hoc paired $t$ test. Values are mean $\pm S E M . b, c$, Continuous frequency plots represent percentage changes in EEG power relative to baseline values taken during microperfusion of aCSF (horizontal line) with either histamine or during the time control period (i.e., continuous aCSF microperfusion). Plots are shown for WT and ChAT-Cre:TASK ${ }^{f / f}$ mice across sleep-wake states. For histamine treatment, group sizes were $n=12 \mathrm{WT}$ and $n=12 \mathrm{ChAT-Cre:TASK}{ }^{\mathrm{f} / f}$ mice. In the aCSF time controls, group sizes were $n=8$ WT and $n=8 \mathrm{ChAT-Cre:TASK}{ }^{\mathrm{f} / f}$ mice. As the EEG is not affected in the time-control experiments, the shift in electrocortical activity is consistent with the action of histamine and not time-of-day effects. Values are mean \pm SEM.

the neural systems generating EEG oscillations (Meuth et al., 2003; Pang et al., 2009). Previous studies identified that global TASK-3 KO mice lacked a halothane-induced $\theta$ oscillation (Pang et al., 2009), exhibited increased motor activity in the active (i.e., dark) phase of the light-dark cycle, and increased fragmentation of sleep bouts (Linden et al., 2007).

For the present study, we used mice with TASK-1/3 channel KO in cholinergic neurons (i.e., ChAT-Cre:TASK ${ }^{f / f}$ mice) (Lazarenko et al., 2010). We show that TASK channels on cholinergic neurons contribute to baseline EEG activity (Fig. 4). For example, in the ChAT-Cre:TASK ${ }^{f / f}$ mice, $4-8 \mathrm{~Hz}$ EEG activity was higher in both NREM sleep and quiet wakefulness, and 12-30 Hz EEG activity was higher in REM sleep, whereas in quiet wakefulness $1-4 \mathrm{~Hz}$ and $30-50 \mathrm{~Hz}$ EEG activity was lower compared with WTs. Cholinergic cell groups involved in generating EEG oscillations include neurons of the basal forebrain (Pinto et al., 2013), medial septum (Yoder and Pang, 2005; Pang et al., 2009), as well as the laterodorsal and pedunculopontine tegmentum (Dringen- berg and Olmstead, 2003). Our results support a role for TASK channels in the cholinergic circuits contributing to endogenous EEG oscillations. Nevertheless, despite the statistically significant changes in endogenous EEG oscillations in the Cre:TASK ${ }^{f f f}$ mice, these differences were small and there was no obvious behavioral phenotype as indicated by normal sleep-wake architecture and total EEG power compared with the WT mice (Fig. 4). Accordingly, we next focused on the role of TASK channels on cholinergic neurons in modulating the electrocortical response to histamine at the basal forebrain in vivo.

\section{Histamine-induced cortical arousal in WT mice}

Histamine is distinct from other wake-active neurotransmitters in that its action is highest during periods of high vigilance (Takahashi et al., 2006) and is selectively associated with wakefulness and consciousness rather than motor activity (John et al., 2004). Our results show that microperfusion of histamine into the basal forebrain modulates arousal state, as evidenced by increased per- 


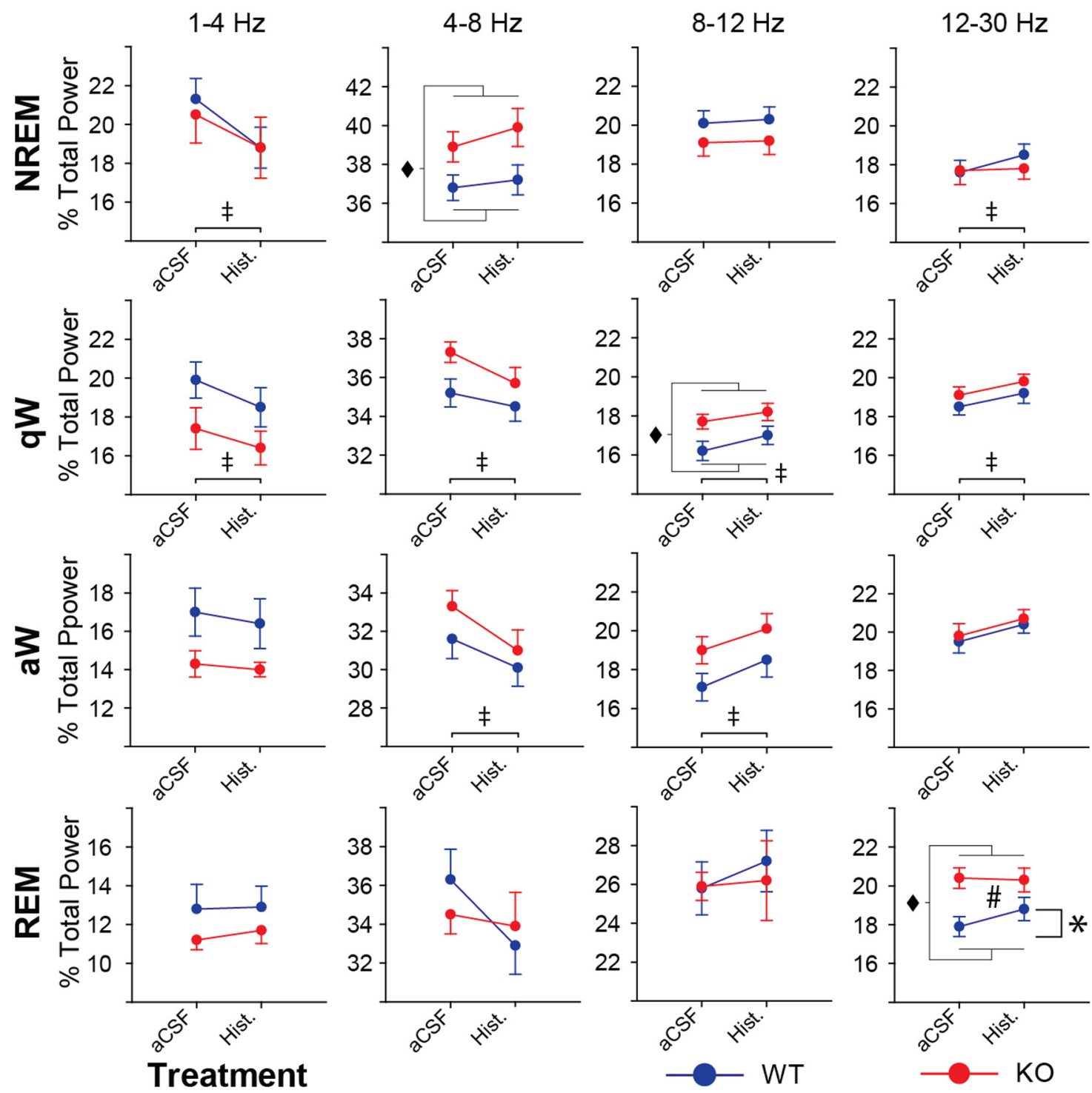

Figure 7. Microperfusion of histamine into the basal forebrain shifts EEG activity in other frequency bands consistent with cortical arousal. Percentage of the total EEG power across sleep-wake states in the 1-4, 4-8, 8-12, and 12-30 Hz frequency bands is shown for WT (blue) and ChAT-Cre:TASK ${ }^{f / f}(K 0$, red) mice. The change in EEG power from aCSF to microperfusion of histamine is shown. Except for $12-30 \mathrm{~Hz}$ power during REM sleep, the effect of $1 \mathrm{~mm}$ histamine is not significantly different between genotypes. Group sizes were $n=12 \mathrm{WT}$ and $n=12 \mathrm{ChAT}^{-\mathrm{Cre}^{2} \mathrm{TASK}}{ }^{\mathrm{f} / \mathrm{m}}$ mice. Groups were compared using a two-way repeated-measures ANOVA (factors being genotype and treatment). $\neq p<0.05$, significant effect of histamine versus aCSF treatment. $p<0.05$, significant effect of genotype. ${ }^{\#} p<0.05$, significant interaction between genotype and the effect of the perfusion medium. ${ }^{*} p<0.05$, significant difference between groups using a post hoc paired $t$ test. Values are mean \pm SEM.

centage of time spent in quiet wakefulness, decreased percentage of time spent in NREM sleep, reduced total EEG power in NREM sleep, quiet wakefulness, and REM sleep, as well as increased 30-50 Hz EEG activity in NREM sleep and quiet wakefulness. Our results are consistent with previous studies in rats showing that $1 \mathrm{~mm}$ histamine microperfused into the basal forebrain can elicit EEG arousal (measured in the $1-20 \mathrm{~Hz}$ range) and wakefulness (Ramesh et al., 2004; Zant et al., 2012), thus providing the precedent for us to test the role of TASK channels in the current study.

Although histamine neurons normally discharge minimally during REM sleep (John et al., 2004; Takahashi et al., 2006), the effects of increased histamine at the basal forebrain on EEG activity during REM sleep may be clinically relevant. One sleep disorder related to intrusions of REM sleep circuitry into waking behavior is narcolepsy with cataplexy. The loss of muscle tone in cataplexy involves cessation of noradrenergic and serotonergic neuronal activity (John et al., 2004). However, the maintenance of conscious awareness is attributed to continued activity of histaminergic neurons (John et al., 2004) and likely involves components of the circuit identified in this paper.

$\gamma$ activity also varies across sleep-wake states (Fig. 4), and the $\gamma$ power can reflect the overall level of arousal in each state (Gross and Gotman, 1999). $\gamma$ oscillations are associated with attentive states and cognitive function (Fries et al., 2001). Of note, microperfusion of histamine into the basal forebrain had minimal effects on $\gamma$ activity in active wakefulness. In WT mice, histamine did not affect the percentage of time spent in active wakefulness or total EEG power (Fig. 5), nor did it affect 30-50 Hz EEG power (Fig. 6). These results may reflect a "ceiling effect" for cortical arousal in vivo such that histamine has minimal effects when the animal is already aroused and further activation of basal forebrain cholinergic neurons is limited. Consistent with this interpretation, a previous in vitro study reported that histamine- 
induced increases in the firing rate of basal forebrain cholinergic neurons plateau at $\sim 8 \mathrm{~Hz}$ regardless of increasing histamine concentration (Khateb et al., 1995). This firing rate of basal forebrain cholinergic neurons in vitro corresponds to the rate recorded in vivo in freely behaving rats during active wakefulness (Szymusiak et al., 2000; Lee et al., 2005). Therefore, it is likely that basal forebrain cholinergic neurons have a maximal firing rate during active wakefulness and that, in WT animals, this ceiling cannot be further raised by histamine at the basal forebrain.

Last, the basal forebrain contains cholinergic, GABAergic, and glutamatergic neurons, and each population receives input from wakefulness-active neurotransmitter systems (Jones, 2004). As noncholinergic basal forebrain neurons are also responsive to histamine (Fort et al., 1998), we cannot exclude the possibility that noncholinergic neurons may mediate a component of the arousing effects of histamine that we observed in the present study. However, cholinergic neuron-specific lesions produced by applying the immunotoxin 192-IgG-saporin into the basal forebrain eliminate the wakefulness-promoting effect of histamine (Zant et al., 2012), indicating that histamine-induced cortical arousal may largely target basal forebrain cholinergic neurons.

\section{Histamine-induced cortical arousal after TASK deletion}

Microperfusion of histamine into the basal forebrain of WT mice induced cortical arousal as evidenced by increased 30-50 Hz EEG activity in NREM sleep and quiet wakefulness, decreased total EEG power in all states except active wakefulness, decreased time spent in NREM sleep, and increased time spent in quiet wakefulness. In ChAT-Cre:TASK ${ }^{f / f}$ mice, there was a significant, statedependent effect of TASK deletion on histamine-induced cortical arousal. The increase in $30-50 \mathrm{~Hz}$ EEG power by histamine during NREM sleep was significantly decreased in the KO mice, suggesting that TASK-1/3 channels on basal forebrain cholinergic neurons contribute to increased $\gamma$ activity induced by histamine.

Conversely, during active wakefulness, histamine increased 30-50 Hz EEG activity in KO mice but not in WTs (Fig. 6). Consistent with this result, histamine increased the percentage of time spent in active wakefulness in $\mathrm{KO}$ mice but had no effect in WTs (Fig. 5). These results suggest that, in the WT mice, there is a "ceiling" on histamine-induced arousal effects during active wakefulness (i.e., when the animal is already aroused and cholinergic basal forebrain neurons are firing maximally, as discussed in the previous section) but that this "ceiling" is not in effect to the same degree in ChAT-Cre:TASK ${ }^{f / f}$ mice.

The reduced "ceiling effect" may be due to the wider impact of cholinergic-specific TASK channel deletion on other wakefulness-active neurotransmitter systems. For example, the noradrenergic, serotonergic, and orexinergic neurotransmitter systems that innervate basal forebrain cholinergic neurons (Jones and Cuello, 1989; Fort et al., 1995; Eggermann et al., 2001) and inhibit TASK channels in vitro (Talley et al., 2000; Doroshenko and Renaud, 2009) may also be attenuated by cholinergic-specific TASK channel deletion. Reduced activating input from these other wake-active neurotransmitters onto basal forebrain cholinergic neurons during active wakefulness may, therefore, influence the extent to which arousal can be further increased by histamine. If basal forebrain cholinergic neurons in ChAT-Cre:TASK ${ }^{f / f}$ mice are firing submaximally during active wakefulness (having not reached the normal "ceiling" on firing rate), then they may be able to increase their activity in response to increased histamine at the basal forebrain.

In conclusion, TASK channels on cholinergic neurons contribute to endogenous EEG oscillations (including $\gamma$ activity) and the electrocortical response to histamine at the basal forebrain in vivo. Findings supporting this conclusion are the lower baseline $30-50 \mathrm{~Hz}$ EEG power in awake mice lacking TASK-1/3 channels on cholinergic neurons (Fig. $4 a$ ) and the attenuated response to histamine in those mice in periods of low arousal (NREM sleep; Fig. 6a), Nevertheless, it is also noted that KO of TASK-1/3 channels on cholinergic neurons did not abolish histamine-induced cortical arousal in vivo, suggesting that other mechanisms in addition to TASK channels are importantly involved. In support of this conclusion are the observations that the histamine-induced increase in $\gamma$ activity was more prominent in the $\mathrm{KO}$ mice compared with the WTs in states of increased arousal (active wakefulness; Fig. 6a) and that the reduction in total EEG power by histamine at the basal forebrain was independent of genotype (Fig. 5b). Histamine receptor stimulation can increase neural activity via several intracellular signaling pathways (Haas and Panula, 2003), and the identification of such non-TASKdependent mechanisms modulating the histamine-basal forebrain cholinergic arousal circuit remains to be determined.

\section{References}

Bayliss DA, Barrett PQ (2008) Emerging roles for two-pore-domain potassium channels and their potential therapeutic impact. Trends Pharmacol Sci 29:566-575. CrossRef Medline

Buzsaki G, Bickford RG, Ponomareff G, Thal LJ, Mandel R, Gage FH (1988) Nucleus basalis and thalamic control of neocortical activity in the freely moving rat. J Neurosci 8:4007-4026. Medline

Carrillo JJ, Pediani J, Milligan G (2003) Dimers of class A G protein-coupled receptors function via agonist-mediated trans-activation of associated $G$ proteins. J Biol Chem 278:42578-42587. CrossRef Medline

Chen X, Talley EM, Patel N, Gomis A, McIntire WE, Dong B, Viana F, Garrison JC, Bayliss DA (2006) Inhibition of a background potassium channel by Gq protein alpha-subunits. Proc Natl Acad Sci U S A 103: 3422-3427. CrossRef Medline

Doroshenko P, Renaud LP (2009) Acid-sensitive TASK-like $\mathrm{K}^{+}$conductances contribute to resting membrane potential and to orexin-induced membrane depolarization in rat thalamic paraventricular nucleus neurons. Neuroscience 158:1560-1570. CrossRef Medline

Dringenberg HC, Olmstead MC (2003) Integrated contributions of basal forebrain and thalamus to neocortical activation elicited by pedunculopontine tegmental stimulation in urethane-anesthetized rats. Neuroscience 119:839-853. CrossRef Medline

Eggermann E, Serafin M, Bayer L, Machard D, Saint-Mleux B, Jones BE, Mühlethaler M (2001) Orexins/hypocretins excite basal forebrain cholinergic neurones. Neuroscience 108:177-181. CrossRef Medline

Enyedi P, Czirják G (2010) Molecular background of leak $\mathrm{K}^{+}$currents: twopore domain potassium channels. Physiol Rev 90:559-605. CrossRef Medline

Fort P, Khateb A, Pegna A, Mühlethaler M, Jones BE (1995) Noradrenergic modulation of cholinergic nucleus basalis neurons demonstrated by in vitro pharmacological and immunohistochemical evidence in the guineapig brain. Eur J Neurosci 7:1502-1511. CrossRef Medline

Fort P, Khateb A, Serafin M, Mühlethaler M, Jones BE (1998) Pharmacological characterization and differentiation of non-cholinergic nucleus basalis neurons in vitro. Neuroreport 9:61-65. CrossRef Medline

Franklin KBJ, Paxinos G (1997) The mouse brain in stereotaxic coordinates. San Diego: Academic.

Franks NP (2008) General anaesthesia: from molecular targets to neuronal pathways of sleep and arousal. Nat Rev Neurosci 9:370-386. CrossRef Medline

Franks NP, Lieb WR (1988) Volatile general anaesthetics activate a novel neuronal $\mathrm{K}^{+}$current. Nature 333:662-664. CrossRef Medline

Fries P, Reynolds JH, Rorie AE, Desimone R (2001) Modulation of oscillatory neuronal synchronization by selective visual attention. Science 291: 1560-1563. CrossRef Medline

Goard M, Dan Y (2009) Basal forebrain activation enhances cortical coding of natural scenes. Nat Neurosci 12:1444-1449. CrossRef Medline

Grace KP, Vanstone LE, Horner RL (2014a) Endogenous cholinergic input to the pontine REM sleep generator is not required for REM sleep to occur. J Neurosci 34:14198-14209. CrossRef Medline 
Grace KP, Hughes SW, Horner RL (2014b) Identification of a pharmacological target for genioglossus reactivation throughout sleep. Sleep 37:41-50. CrossRef Medline

Gross DW, Gotman J (1999) Correlation of high-frequency oscillations with the sleep-wake cycle and cognitive activity in humans. Neuroscience 94:1005-1018. CrossRef Medline

Haas H, Panula P (2003) The role of histamine and the tuberomamillary nucleus in the nervous system. Nat Rev Neurosci 4:121-130. CrossRef Medline

Inagaki $\mathrm{N}$, Yamatodani $\mathrm{A}$, Ando-Yamamoto $\mathrm{M}$, Tohyama $\mathrm{M}$, Watanabe $\mathrm{T}$, Wada H (1988) Organization of histaminergic fibers in the rat brain. J Comp Neurol 273:283-300. CrossRef Medline

John J, Wu MF, Boehmer LN, Siegel JM (2004) Cataplexy-active neurons in the hypothalamus: implications for the role of histamine in sleep and waking behavior. Neuron 42:619-634. CrossRef Medline

Jones BE (2004) Activity, modulation and role of basal forebrain cholinergic neurons innervating the cerebral cortex. Prog Brain Res 145:157-169. CrossRef Medline

Jones BE, Cuello AC (1989) Afferents to the basal forebrain cholinergic cell area from pontomesencephalic — catecholamine, serotonin, and acetylcholine-neurons. Neuroscience 31:37-61. CrossRef Medline

Kang Y, Dempo Y, Ohashi A, Saito M, Toyoda H, Sato H, Koshino H, Maeda Y, Hirai T (2007) Nitric oxide activates leak $\mathrm{K}^{+}$currents in the presumed cholinergic neuron of basal forebrain. J Neurophysiol 98:33973410. CrossRef Medline

Khateb A, Fort P, Pegna A, Jones BE, Mühlethaler M (1995) Cholinergic nucleus basalis neurons are excited by histamine in vitro. Neuroscience 69:495-506. CrossRef Medline

Larkman PM, Perkins EM (2005) A TASK-like pH- and amine-sensitive 'leak' $\mathrm{K}^{+}$conductance regulates neonatal rat facial motoneuron excitability in vitro. Eur J Neurosci 21:679-691. CrossRef Medline

Lazarenko RM, Willcox SC, Shu S, Berg AP, Jevtovic-Todorovic V, Talley EM, Chen X, Bayliss DA (2010) Motoneuronal TASK channels contribute to immobilizing effects of inhalational general anesthetics. J Neurosci 30: 7691-7704. CrossRef Medline

Lee MG, Hassani OK, Alonso A, Jones BE (2005) Cholinergic basal forebrain neurons burst with theta during waking and paradoxical sleep. J Neurosci 25:4365-4369. CrossRef Medline

Lee SH, Dan Y (2012) Neuromodulation of brain states. Neuron 76:209222. CrossRef Medline

Lesage F, Barhanin J (2011) Molecular physiology of pH-sensitive background K(2P) channels. Physiology 26:424-437. CrossRef Medline

Li Z, Hatton GI (1996) Histamine-induced prolonged depolarization in rat supraoptic neurons: G-protein-mediated, $\mathrm{Ca}(2+)$-independent suppression of $\mathrm{K}^{+}$leakage conductance. Neuroscience 70:145-158. CrossRef Medline

Linden AM, Sandu C, Aller MI, Vekovischeva OY, Rosenberg PH, Wisden W, Korpi ER (2007) TASK-3 knockout mice exhibit exaggerated nocturnal activity, impairments in cognitive functions, and reduced sensitivity to inhalation anesthetics. J Pharmacol Exp Ther 323:924-934. CrossRef Medline

Linkert M, Rueden CT, Allan C, Burel JM, Moore W, Patterson A, Loranger B, Moore J, Neves C, Macdonald D, Tarkowska A, Sticco C, Hill E, Rossner M, Eliceiri KW, Swedlow JR (2010) Metadata matters: access to image data in the real world. J Cell Biol 189:777-782. CrossRef Medline

Liu X, Sood S, Liu H, Horner RL (2005) Opposing muscarinic and nicotinic modulation of hypoglossal motor output to genioglossus muscle in rats in vivo. J Physiol 565:965-980. CrossRef Medline

Marinc C, Preisig-Müller R, Prüss H, Derst C, Veh RW (2011) Immunocytochemical localization of TASK-3 (K(2P)9.1) channels in monoaminergic and cholinergic neurons. Cell Mol Neurobiol 31:323-335. CrossRef Medline

McCormick DA, Williamson A (1991) Modulation of neuronal firing mode in cat and guinea pig LGNd by histamine: possible cellular mechanisms of histaminergic control of arousal. J Neurosci 11:3188-3199. Medline

Mesbah-Oskui L, Orser BA, Horner RL (2014) Thalamic $\delta$-subunit containing GABAA receptors promote electrocortical signatures of deep nonREM sleep but do not mediate the effects of etomidate at the thalamus in vivo. J Neurosci 34:12253-12266. CrossRef Medline

Meuth SG, Budde T, Kanyshkova T, Broicher T, Munsch T, Pape HC (2003) Contribution of TWIK-related acid-sensitive $\mathrm{K}^{+}$channel 1 (TASK1) and
TASK3 channels to the control of activity modes in thalamocortical neurons. J Neurosci 23:6460-6469. Medline

Montandon G, Qin W, Liu H, Ren J, Greer JJ, Horner RL (2011) PreBotzinger complex neurokinin-1 receptor-expressing neurons mediate opioid-induced respiratory depression. J Neurosci 31:1292-1301. CrossRef Medline

Morrison JL, Sood S, Liu X, Liu H, Park E, Nolan P, Horner RL (2002) Glycine at hypoglossal motor nucleus: genioglossus activity, $\mathrm{CO}_{2}$ responses, and the additive effects of GABA. J Appl Physiol 93:1786-1796. CrossRef Medline

Morrison JL, Sood S, Liu H, Park E, Nolan P, Horner RL (2003) GABAA receptor antagonism at the hypoglossal motor nucleus increases genioglossus muscle activity in NREM but not REM sleep. J Physiol 548:569583. CrossRef Medline

Moruzzi G, Magoun HW (1949) Brain stem reticular formation and activation of the EEG. Electroencephalogr Clin Neurophysiol 1:455-473. CrossRef Medline

Nelson LE, Guo TZ, Lu J, Saper CB, Franks NP, Maze M (2002) The sedative component of anesthesia is mediated by GABA(A) receptors in an endogenous sleep pathway. Nat Neurosci 5:979-984. CrossRef Medline

Oh SW, Harris JA, Ng L, Winslow B, Cain N, Mihalas S, Wang Q, Lau C, Kuan L, Henry AM, Mortrud MT, Ouellette B, Nguyen TN, Sorensen SA, Slaughterbeck CR, Wakeman W, Li Y, Feng D, Ho A, Nicholas E, et al. (2014) A mesoscale connectome of the mouse brain. Nature 508:207214. CrossRef Medline

Pang DS, Robledo CJ, Carr DR, Gent TC, Vyssotski AL, Caley A, Zecharia AY, Wisden W, Brickley SG, Franks NP (2009) An unexpected role for TASK-3 potassium channels in network oscillations with implications for sleep mechanisms and anesthetic action. Proc Natl Acad Sci U S A 106 : 17546-17551. CrossRef Medline

Patel AJ, Honoré E, Lesage F, Fink M, Romey G, Lazdunski M (1999) Inhalational anesthetics activate two-pore-domain background $\mathrm{K}^{+}$channels. Nat Neurosci 2:422-426. CrossRef Medline

Pinto L, Goard MJ, Estandian D, Xu M, Kwan AC, Lee SH, Harrison TC, Feng G, Dan Y (2013) Fast modulation of visual perception by basal forebrain cholinergic neurons. Nat Neurosci 16:1857-1863. CrossRef Medline

Portas CM, Thakkar M, Rainnie D, McCarley RW (1996) Microdialysis perfusion of 8-hydroxy-2-(di- $n$-propylamino)tetralin (8-OH-DPAT) in the dorsal raphe nucleus decreases serotonin release and increases rapid eye movement sleep in the freely moving cat. J Neurosci 16:2820-2828. Medline

Ramesh V, Thakkar MM, Strecker RE, Basheer R, McCarley RW (2004) Wakefulness-inducing effects of histamine in the basal forebrain of freely moving rats. Behav Brain Res 152:271-278. CrossRef Medline

Reiner PB, Kamondi A (1994) Mechanisms of antihistamine-induced sedation in the human brain: $\mathrm{H} 1$ receptor activation reduces a background leakage potassium current. Neuroscience 59:579-588. CrossRef Medline

Schneider CA, Rasband WS, Eliceiri KW (2012) NIH Image to ImageJ: 25 years of image analysis. Nat Methods 9:671-675. CrossRef Medline

Semba K, Reiner PB, McGeer EG, Fibiger HC (1988) Brainstem afferents to the magnocellular basal forebrain studied by axonal transport, immunohistochemistry, and electrophysiology in the rat. J Comp Neurol 267:433453. CrossRef Medline

Sirois JE, Lei Q, Talley EM, Lynch C 3rd, Bayliss DA (2000) The TASK-1 two-pore domain $\mathrm{K}^{+}$channel is a molecular substrate for neuronal effects of inhalation anesthetics. J Neurosci 20:6347-6354. Medline

Sood S, Liu X, Liu H, Nolan P, Horner RL (2003) 5-HT at hypoglossal motor nucleus and respiratory control of genioglossus muscle in anesthetized rats. Respir Physiol Neurobiol 138:205-221. CrossRef Medline

Steinberg EA, Wafford KA, Brickley SG, Franks NP, Wisden W (2015) The role of K channels in anaesthesia and sleep. Pflugers Arch 467:907-916. CrossRef Medline

Szymusiak R, Alam N, McGinty D (2000) Discharge patterns of neurons in cholinergic regions of the basal forebrain during waking and sleep. Behav Brain Res 115:171-182. CrossRef Medline

Takahashi K, Lin JS, Sakai K (2006) Neuronal activity of histaminergic tuberomammillary neurons during wake-sleep states in the mouse. J Neurosci 26:10292-10298. CrossRef Medline

Talley EM, Bayliss DA (2002) Modulation of TASK-1 (Kcnk3) and TASK-3 (Kcnk9) potassium channels: volatile anesthetics and neurotransmitters 
share a molecular site of action. J Biol Chem 277:17733-17742. CrossRef Medline

Talley EM, Lei Q, Sirois JE, Bayliss DA (2000) TASK-1, a two-pore domain $\mathrm{K}^{+}$channel, is modulated by multiple neurotransmitters in motoneurons. Neuron 25:399-410. CrossRef Medline

Tang X, Orchard SM, Liu X, Sanford LD (2004) Effect of varying recording cable weight and flexibility on activity and sleep in mice. Sleep 27:803810. Medline

Toyoda H, Saito M, Sato H, Dempo Y, Ohashi A, Hirai T, Maeda Y, Kaneko T, Kang Y (2008) cGMP activates a pH-sensitive leak $\mathrm{K}^{+}$current in the presumed cholinergic neuron of basal forebrain. J Neurophysiol 99: 2126-2133. CrossRef Medline

Toyoda H, Saito M, Okazawa M, Hirao K, Sato H, Abe H, Takada K, Funabiki K, Takada M, Kaneko T, Kang Y (2010) Protein kinase G dynamically modulates TASK1-mediated leak $\mathrm{K}^{+}$currents in cholinergic neurons of the basal forebrain. J Neurosci 30:5677-5689. CrossRef Medline

Weber M, Schmitt A, Wischmeyer E, Döring F (2008) Excitability of pontine startle processing neurones is regulated by the two-pore-domain $\mathrm{K}^{+}$ channel TASK-3 coupled to 5-HT2C receptors. Eur J Neurosci 28:931940. CrossRef Medline

Wilke BU, Lindner M, Greifenberg L, Albus A, Kronimus Y, Bünemann M, Leitner MG, Oliver D (2014) Diacylglycerol mediates regulation of TASK potassium channels by Gq-coupled receptors. Nat Commun 5:5540. CrossRef Medline

Yoder RM, Pang KC (2005) Involvement of GABAergic and cholinergic medial septal neurons in hippocampal theta rhythm. Hippocampus 15:381392. CrossRef Medline

Zant JC, Rozov S, Wigren HK, Panula P, Porkka-Heiskanen T (2012) Histamine release in the basal forebrain mediates cortical activation through cholinergic neurons. J Neurosci 32:13244-13254. CrossRef Medline

Zecharia AY, Yu X, Götz T, Ye Z, Carr DR, Wulff P, Bettler B, Vyssotski AL, Brickley SG, Franks NP, Wisden W (2012) GABAergic inhibition of histaminergic neurons regulates active waking but not the sleep-wake switch or propofol-induced loss of consciousness. J Neurosci 32:13062-13075. CrossRef Medline 